\title{
Investigating Intersystemic Relations between Iran's Constitutional Literature and French Literary System: A Comparative Literary Study
}

\author{
Abdollah Karimzadeh \\ The Universities of Bergamo (Italy) and Tubingen (Germany) \\ Elaheh Bayatzarand \\ The Islamic Azad University, Central Tehran Branch, Iran
}

\begin{abstract}
The present study builds on data collected through Persian literary corpora. It sets out to investigate the Iranian literary polysystem during and after the Constitutional Revolution of 1906-1911, so-called Postconstitutional literature. In so doing, first Even-Zohar's theory of intersystemic interferences of literary polysystems is discussed and then on the basis of this framework, a comparative literary study is carried out between two Iranian novels(Shams-o Toghra and Eshgh-Saltanat) and the translations of two French novels(The Count of Monte Cristo and The Three Mosketeers). The results seem to support the conclusion that the Iranian works are an imitation of the latter both in their form and content. Since Shams-o Toghra and Eshgh-o Saltanat are the earliest experimentations of Iranian novelists, it is concluded that novel in Iran is a new genre imported through intersystemic contacts between French and Persian Polysyste.
\end{abstract}

Index Terms - comparative literatures, literary polysystem, intersystemic interferences, rise of novel

\section{INTRODUCTION}

Literature according to Even-Zohar (1990, p.30), is a set of socio-cultural activities which in terms of systemic relations behaves as a whole. A literary system itself is defined as "a system of functions of literary order which are in continual interrelationship with other orders"(Munday, 2001, p.109).Literature is thus a part of the social, cultural, literary and historical framework and the key concept is the system in which there is an ongoing struggle for the primary position in the literary canon.Even-Zohar (1990, p.19) terms it as canonization process, or struggle for canonization.

He states that in literature certain properties become canonized, while others remain non-canonized. By canonized, he means that literary norms and works (i.e., both models and texts) which are accepted as legitimate by dominant circles within a culture and those conspicuous products are preserved by the community to become part of its historical heritage. On the other hand, non-canonized means those norms and texts which are rejected by these circles as illegitimate. The struggle between canonized and non-canonized literature is one of the manifestations of a literary system.

Interference is another phenomenon observed in literary systems. Interference can be defined as" a relationship between systems, hereby a certain system A (source system) may become a source for other system B (target system)"(Even-Zohar, 1990.p.93).This phenomenon occurs when a target system does not possess a sufficient repertoire for newly needed functions. According to Even-Zohar (1990), interference tends to happen when systems are in a state of emergence (that is, are new and young) or at turning points in their history. Thus, whenever in need of innovation, a system tends to benefit from another richer system. On the basis of this framework, we are making an attempt to analyze the intersystemic relations between Persian and French polysystems during the emergence of Iranian Constitutional literature.

Inasmuch as the Constitutional Revolution in Iran (1906-1911) marks the beginning of modernization process in socio-cultural structures of the society, the need to feed on western models in this period is felt more strongly than ever. Persian literary system also was in need for innovation. As Sepanlou (2002, p.25) points out, the Persian prose needed transfusing blood in order to fabricate stories, newspapers and literary essays and this was made possible through translating from French polysystem,i.e.,French literary system was injected into Persian polysystem, enriching its repertoire.

In order to shed light on how this system developed and that how new literary genres and styles in Persian literature rose, the relations between systems and sub-systems should be determined in that as Even-Zohar (1990) puts it, both literature and translation systems are sub-systems of cultural polysystem, which may affect or be affected by the social and political developments of the society. To this end, we have chosen the Constitutional literature as the corpus of our study. The rational behind this choice is that the literature of this era has been influenced by a series of socio-cultural and political events, having inspired in particular from French literature. 
Thanks to interferences between Persian and French literary systems, new literary genres including novel and short story have been introduced to Persian literary repertoire. We intend to show how French polysystem especially Alexandre Dumas' works has contributed to the rise of novel in Iran. According to Balay (1998, p.445) Dumas' works are the most influential ones to give rise to the rise of Persian novel.

The present paper aims to establish that the earlier Persian novels are the offspring of Alexandre Dumas' novels.

\section{Corpus of the study}

As to the corpus of this study, two French novels by Alexandre Dumas and two Persian native novels were selected. The Persian novels are the first modern novels produced in Iran. The rational behind selecting these corpora are that Dumas has been imitated by first Iranian novelists. The novels to be compared here are as follows:

1. Shams-o Toghra by Mohammad Bagher Mirza Khosravi,

2. Eshgh-o Saltanat by Sheikh Musa Nasri Hamedani,

3. The Count of Mounte Cristo by Alexandre Dumas,

4. The Three Musketeers by Alexandre Dumas

According to Balay (1998, p.445), Shams-o Toghra and Eshgh-o saltanat are the first modern novels of Iran. The former was produced in 1908 and the latter in 1919.

\section{The Origins of Persian Novel}

Novel is a complicated phenomenon which does not rise suddenly." It is offspring of a crisis"(Balay,1998,p.10). So, in order to explore the origins of novel in a country,its socio-cultural and political crises should be examined.For example, the rise of novel in Iran has its roots in the Constitutional Revolution(Mir Abedini 2007,p.21).Many sociocultural factors also contributed to its emergence including dispatching Iranian students abroad for education ,importing printing press for publishing newspapers and magazine,establishing Dar-ol Fonun,translating foreign works for cultural enrichment.

Balay (1998, p.9) also holds that "novel is the offspring of two cultures". In the Qajarid period when Iran encountered with European culture, some western elements including the genres of novel and short story were digested by Persian literary polysystem.

Persian translations from French literature, in particular alexander Dumas' works have been the major source of inspiration for the rise of Persian novel. Following, we will compare Persian translations of Dumas' works with the first native novels in Iran.

\section{Comparative analysis of the novels}

Before beginning the analysis, it is noteworthy to provide a plot synopsis of Shams-o Toghra and Eshgh-o Saltanat.The aim of the present analysis is to prove that Persian novels are the direct imitations from the translations of the French novels. They have imitated the form and content as well as the narrative techniques of French novels, adopting them to Iranian context.

\section{Plot of Shams-Toghra}

The theme of the novel is love. Shams is the protagonist of the novel. His father is the head of the Deylamids in province of Fars.His father and he come to Shiraz to welcome the new ruler of Fars, who is Mongolian. The ruler's house gets fire and Shams saves his daughter, Toghra.This event is the beginning of their romance.

The problem with Shams and Toghra is that Shams is Iranian, while Toghra is Mongholian. According to the Mongolians' law, the marriage of a Mongol girl to a non-Mongolian is not allowed. Shams would like to marry Toghra legally. To this end, he attempts to find a position in the court of the Mongolians. Soon; he proves his bravery, attracting the queen to himself. In the course of the events, he comes across a treasure which had been hidden by his grandfather. Thus, he becomes well-to-do and buys a mansion in Shiraz and practices generosity, which wins him popularity.

Meanwhile, two love rivals pop up, both of whom fall in love with Toghra.Shams joins the army of the Egyptians and with a tact manages to transmit Toghra to Egypt. This time, an Egyptian price falls in love with Toghra.Shams is taken captive by the Christians in Palestine. He is transmitted to Greece by a ship where a Christian priest buys him, adopting him as his son. Ultimately; Sheikh Sa'adi Shiraz concludes their marriage.

In writing this novel, Khosrarvi has imitated Alexander Dumas and the researchers are going to prove these imitations.

\section{Eshgh-o saltanat}

It depicts the adventures of Cyrus the Great since his birth time to the fall of Babel. How Cyrus came to throne, his conquest of Minor Asia and Babel constitutes the historical context of this novel. But, it is based on the intrigue of love, i.e., the romance between prince Cyaxares (son of Media king) and princess Jupiter (daughter of Lydia king) from the one hand and the romance between prince Hormoz(an Iranian Prince) and princess Oridis(a Babylonian princess) on the other hand. There is also another romance between Farrokh (an Iranian prince) and an Egyptian princess.

\section{METHOdOLOGY OF THE ANALYSIS}

In this analysis, both the form and content of the novels have been explored and all common elements between them have been extracted. An attempt has been made to extract all narrative techniques in French novels which have been imported to Persian Literary system through translation.

\section{Digression}


Digression is a technique in which the narrator leaves a part of the story to focus on another part. This technique has frequently been employed by Alexandre Duma in his multiple-intrigue novels. Since Persian traditional stories were linear (mono-intrigue), classic Persian Polysystem was lacking in this narrative technique. It was imported to Iran's literary system through translation system. Here one can see how the Iranian novelist has imitated Dumas' directly.

\begin{tabular}{|c|c|}
\hline Translated text into Persian & Original Persian text \\
\hline 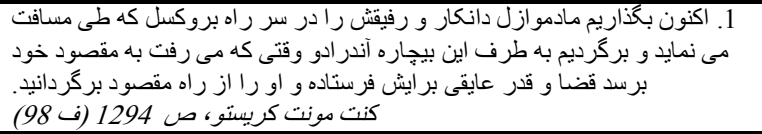 & 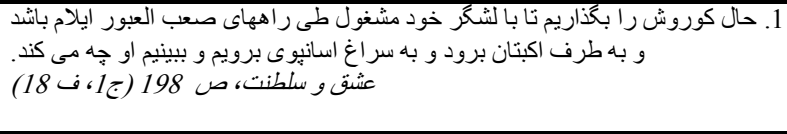 \\
\hline 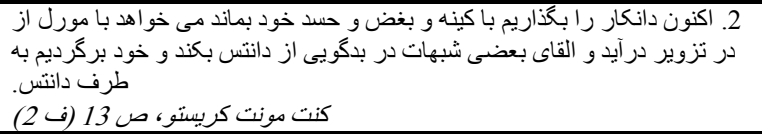 & 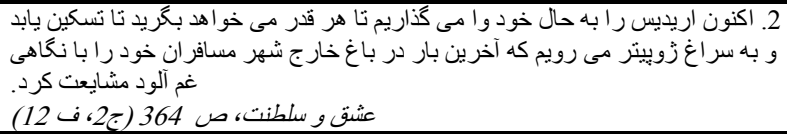 \\
\hline 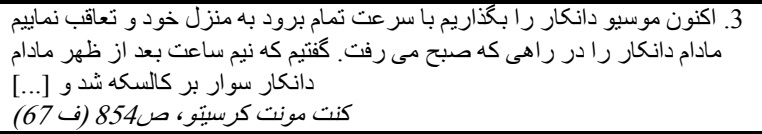 & 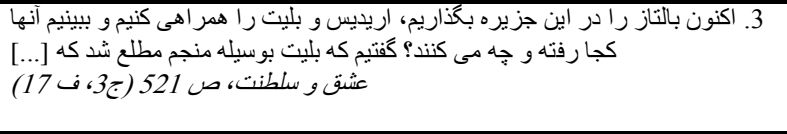 \\
\hline 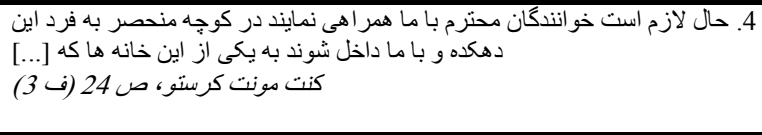 & 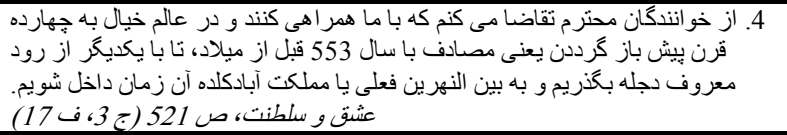 \\
\hline
\end{tabular}

\section{Characterization}

The protagonists in all four novels have been characterized in the same manner.

\begin{tabular}{|c|c|}
\hline Translated text into Persian & Original Persian text \\
\hline Description of Dartanian, the protagonist of The three Musketeers & Description of Egradat, the protagonist of Eshgh-o-Saltanat \\
\hline 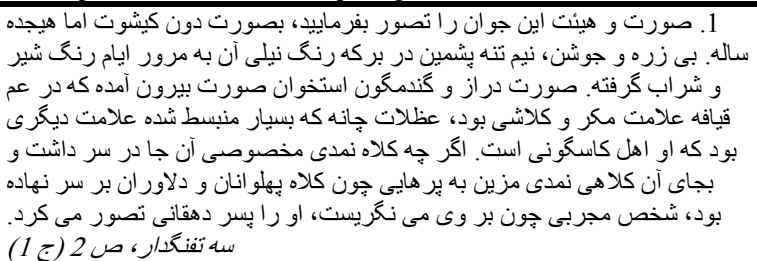 & 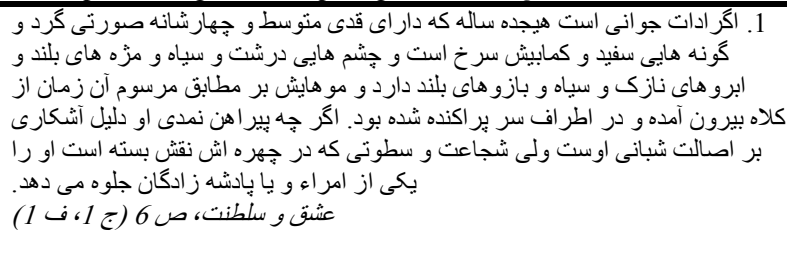 \\
\hline $\begin{array}{l}\text { Description of Edmond Dantès, the protagonist of The Count of } \\
\text { Monte Cristo }\end{array}$ & Description of Shams, the protagonist of Shams-o-Toghra \\
\hline 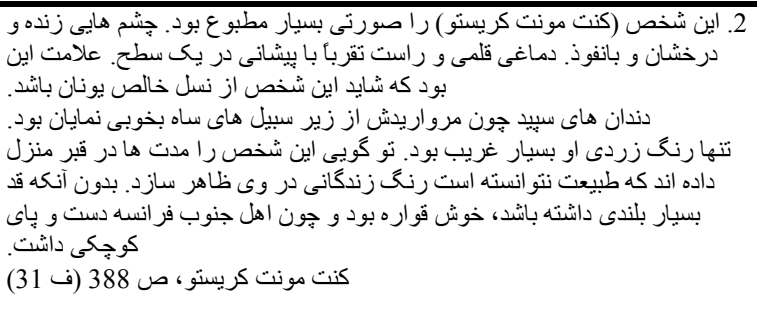 & 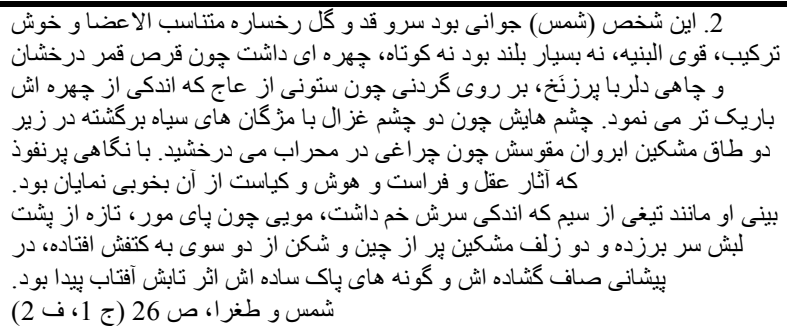 \\
\hline
\end{tabular}

\section{The opening scene setting}

Dumas introduces the setting of his novels from the very beginning. Immediately he shifts to characterization. The same technique has been imitated by the Iranian novelists.

\begin{tabular}{|c|c|}
\hline Translated text into Persian & Original Persian text \\
\hline 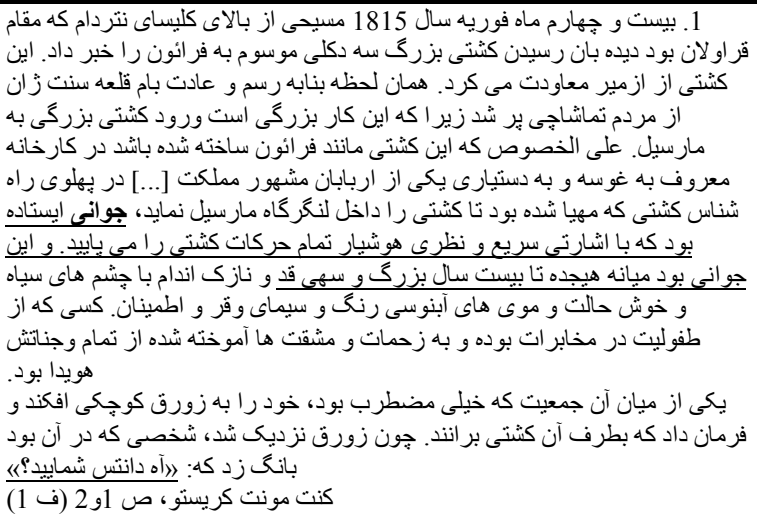 & 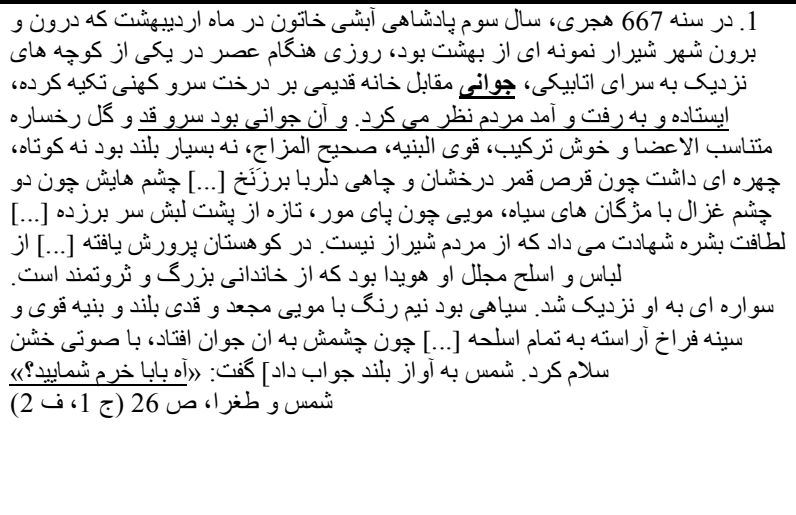 \\
\hline
\end{tabular}




\section{Describing the functional spaces}

Functional or strategic spaces are those playing a specific part in the intrigue of the story (Balay, 1998, p. 510). For describing them at the beginning of the chapters, Dumas provides their historical background and geographical situations. It is done with a documentary language. This technique has been imitated in Iranian novels.

\begin{tabular}{|c|c|}
\hline Translated text into Persian & Original Persian text \\
\hline $\begin{array}{l}\text { Chapter three: } \\
\text { The village of Catalan }\end{array}$ & $\begin{array}{l}\text { Chapter ten: } \\
\text { The city of Pazargad }\end{array}$ \\
\hline 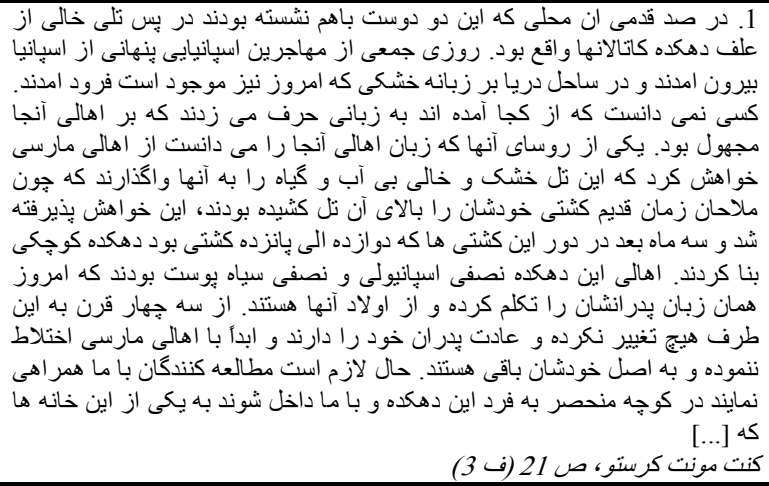 & 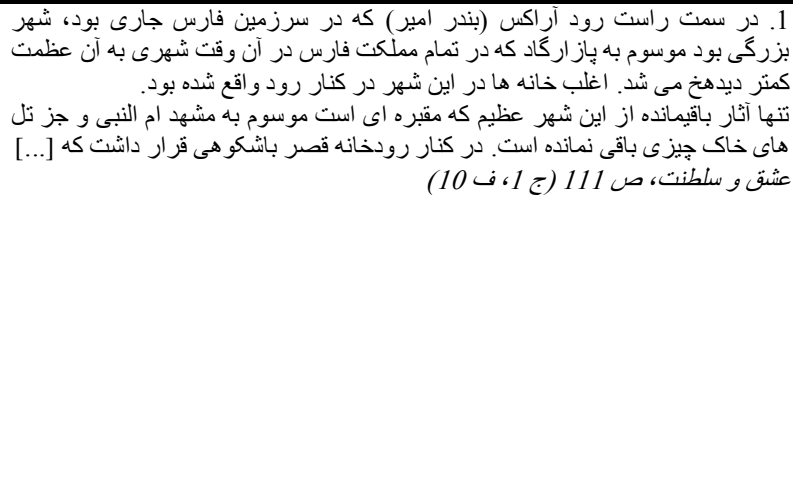 \\
\hline
\end{tabular}

\section{Poetical allusions}

The technique of using poetical allusions as a technique of text production is seen in all four novels. It is noteworthy that this technique already existed in Persian classic literature, but since it lacked in the genres of novel and short story, this technique used to be applied for anecdotes like that of Sa'adi.

\begin{tabular}{|c|c|}
\hline Translated text into Persian & Original Persian text \\
\hline 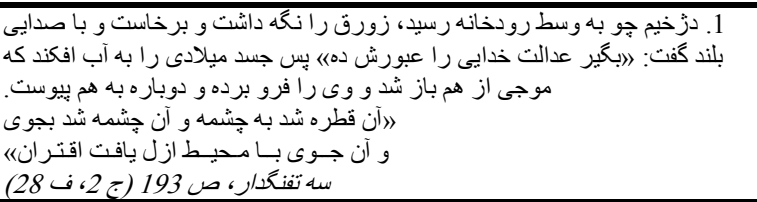 & 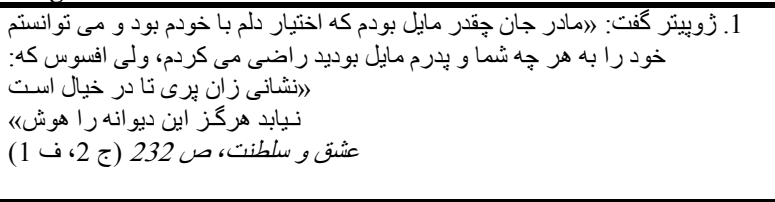 \\
\hline 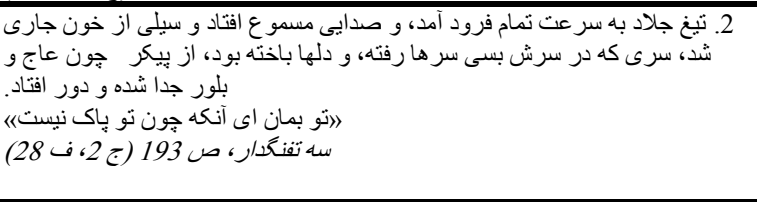 & 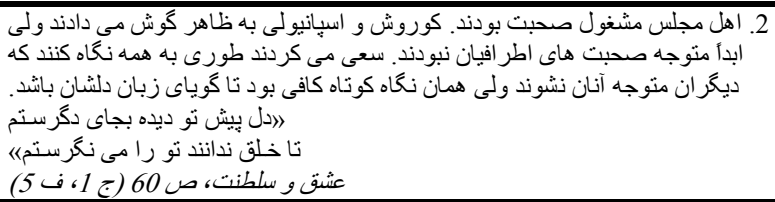 \\
\hline 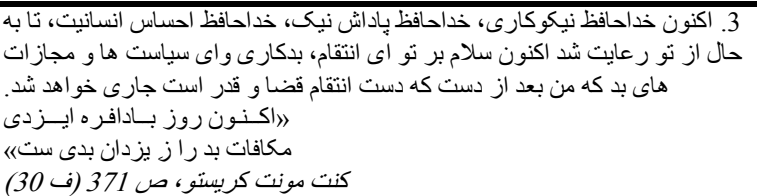 & 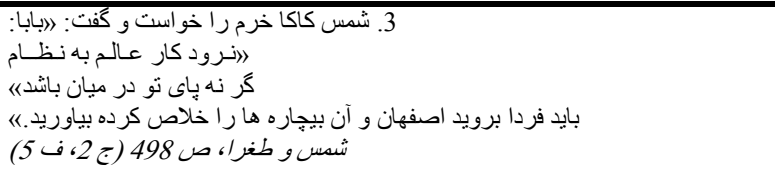 \\
\hline
\end{tabular}

\section{Intertextualization to divine books.}

Intertextuality from divine books can be seen in all three novels.

\begin{tabular}{|c|c|}
\hline Translated text into Persian & Original Persian text \\
\hline 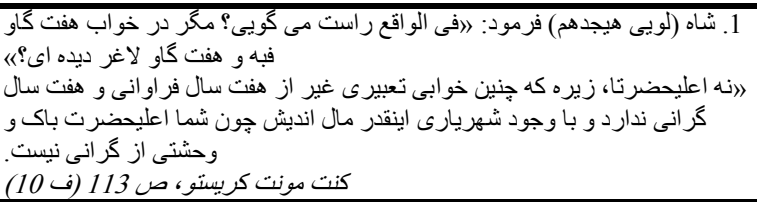 & 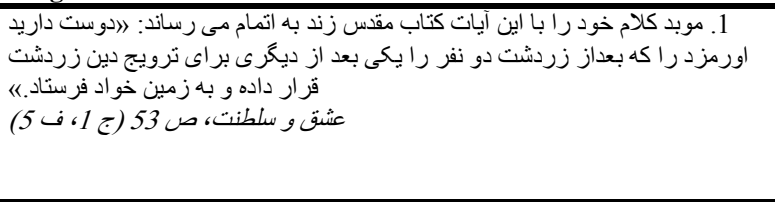 \\
\hline 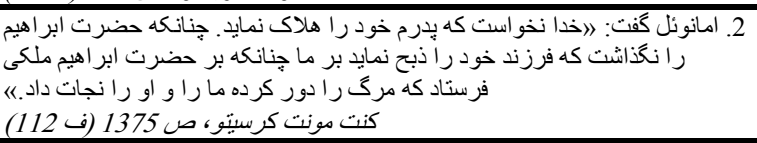 & \multirow[t]{2}{*}{ 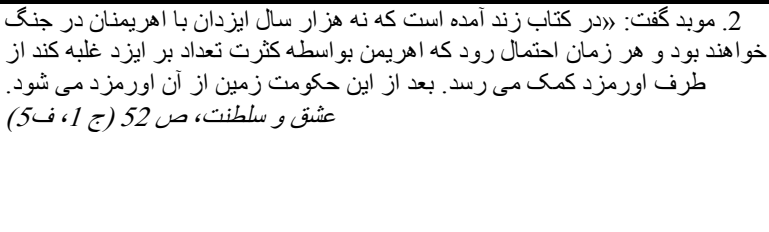 } \\
\hline 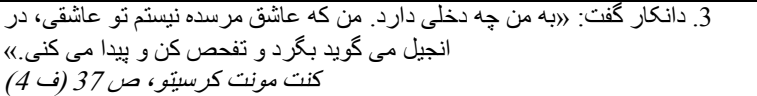 & \\
\hline
\end{tabular}

\section{Imitation in content 1}

The people in love in all three novels cannot marry each other due to irrevocable intermarriage laws. 


\begin{tabular}{|c|c|}
\hline Translated text into Persian & Original Persian text \\
\hline \multirow{2}{*}{ 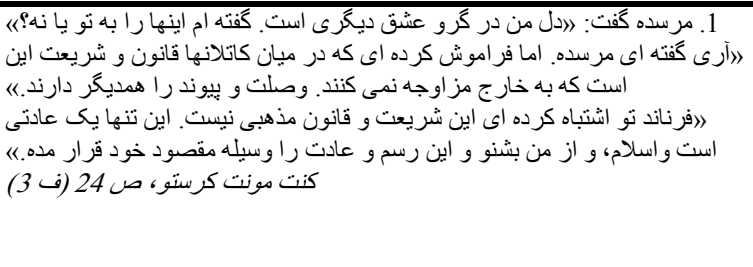 } & 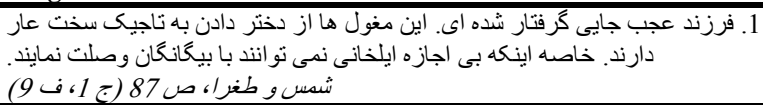 \\
\hline & 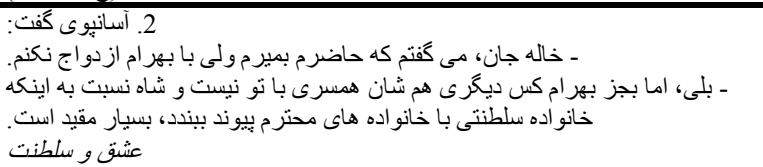 \\
\hline
\end{tabular}

\section{Imitation in content 2}

Arranged marriage is seen in all the novels. The beloved is forced to marry another person.

\begin{tabular}{|c|c|}
\hline Translated text into Persian & Original Persian text \\
\hline 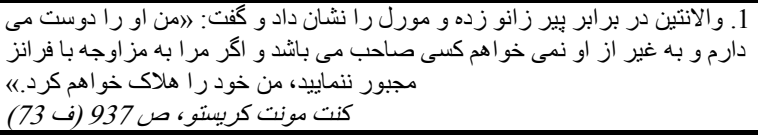 & 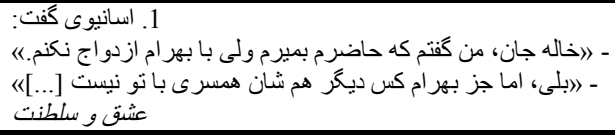 \\
\hline
\end{tabular}

\section{Imitation in content 3}

All three novels are based on the intrigue of love and war. War separates the lover from his sweetheart. In The Count of Monte Cristo four police officers come to his wedding celebration arresting him on charge of being Bonapartist and sentencing him to life imprisonment. The same intrigue is true for the Persian novels.

\begin{tabular}{|c|c|}
\hline Translated text into Persian & Original Persian text \\
\hline 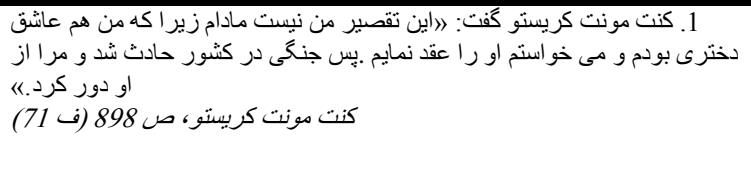 & 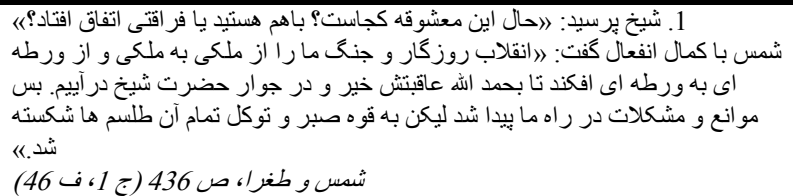 \\
\hline
\end{tabular}

\section{Imitation in content 4}

The protagonists in both novels inherit a huge treasure.

\begin{tabular}{|c|c|}
\hline Translated text into Persian & Original Persian text \\
\hline Cardinal Spada's treasure & Azd-od-Dowleh's treasure \\
\hline 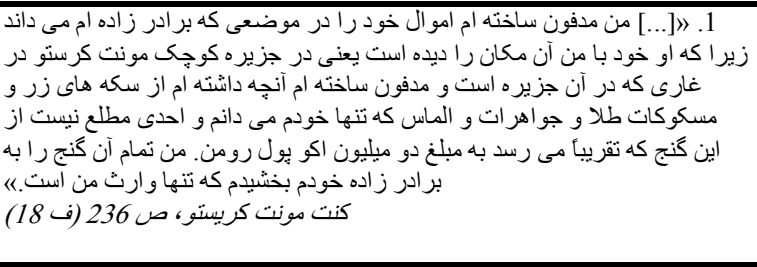 & 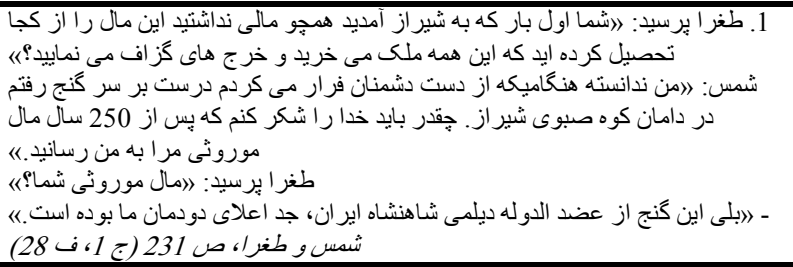 \\
\hline Contents of the treasury & Contents of the treasury \\
\hline 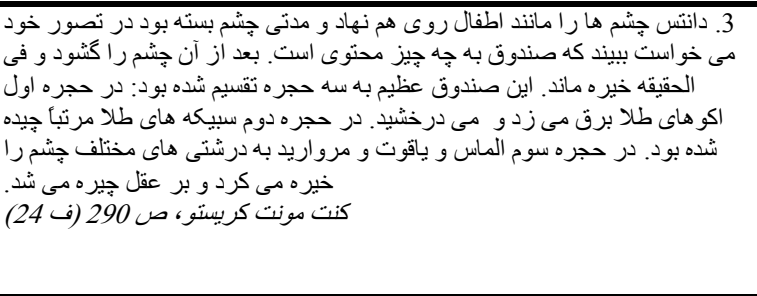 & 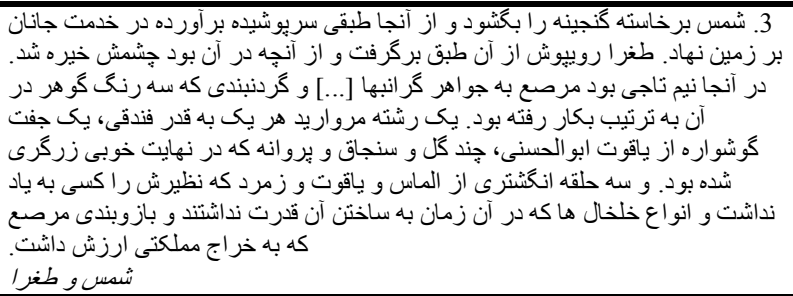 \\
\hline
\end{tabular}

\section{Imitation in content 5}

The protagonists in both novels embark on buying the most expensive buildings and lands of the city and then put up a mansion. 


\begin{tabular}{|c|c|}
\hline Translated text into Persian & Original Persian text \\
\hline Buying the mansion of Champs-Élysées & Buying the mansion of Bagh-e-Takht \\
\hline \multirow[t]{2}{*}{ 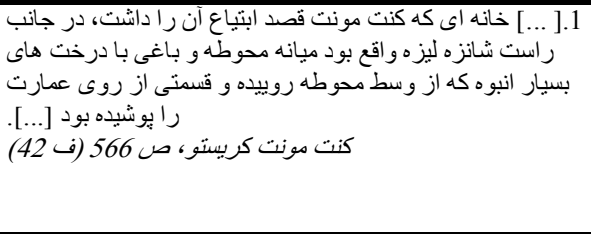 } & 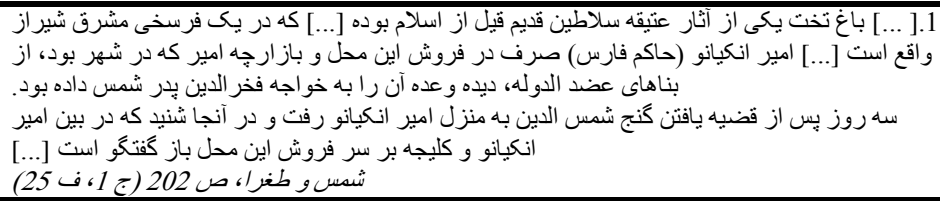 \\
\hline & 2. شمس برخاسته، كفت: \\
\hline 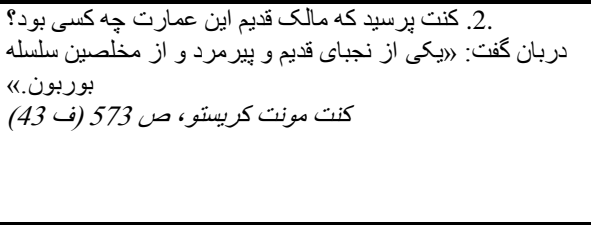 & 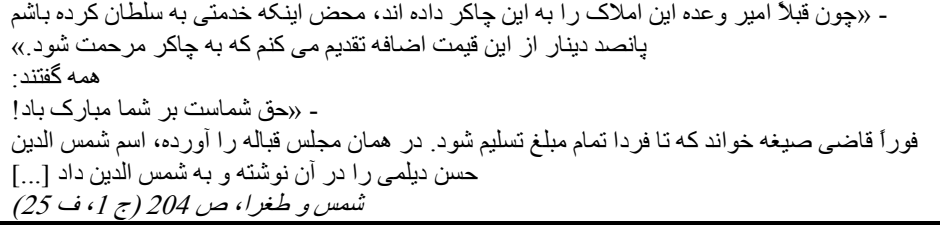 \\
\hline
\end{tabular}

\section{Imitation in content 6}

The protagonists in both novels furnish their mansions with the most expensive stylish furniture. In both mansions there are secret passageways.

\begin{tabular}{|c|c|}
\hline Translated text into Persian & Original Persian text \\
\hline 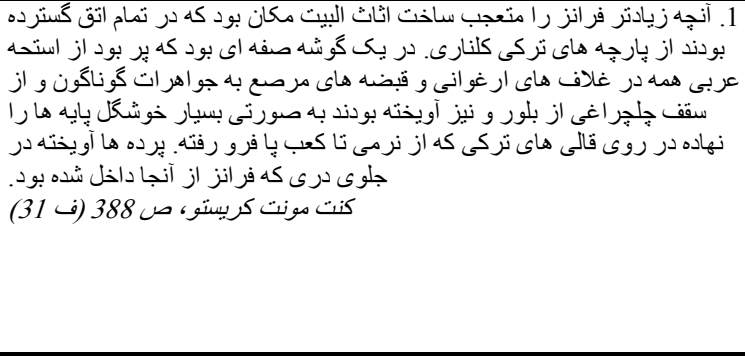 & 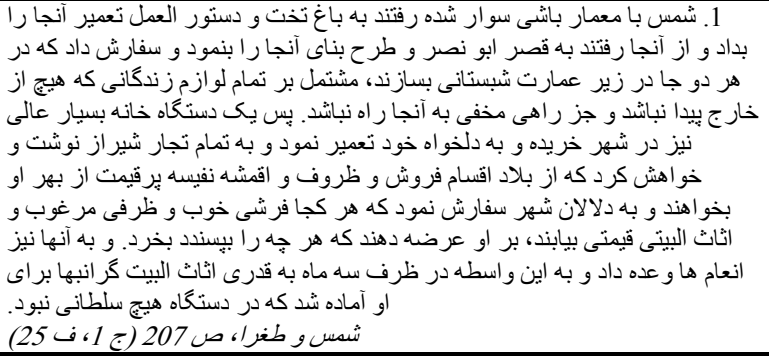 \\
\hline 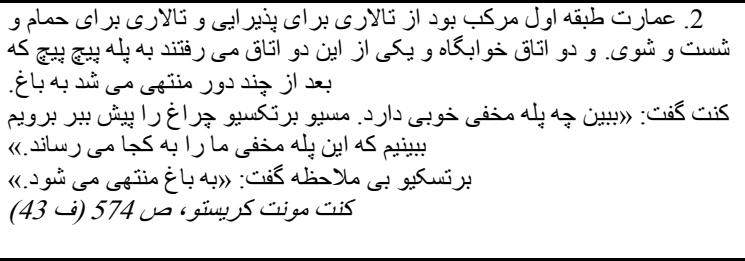 & 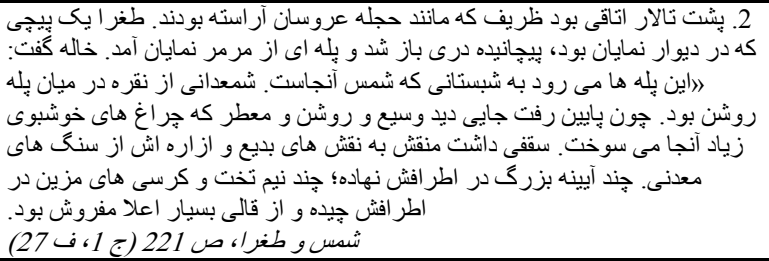 \\
\hline
\end{tabular}

\section{Imitation in content 7}

The protagonists in both novels spend the treasure in the way of taking their revenge on the enemies and helping their real friends. So, the function of the treasure in both cases is revenge. Shams seeks to take his revenge on the Mongolians and take back the lost power of his ancestors (the Deylamid dynasty). But Monte Cristo seeks to take his revenge on those who had betrayed him.

\begin{tabular}{|c|c|}
\hline Translated text into Persian & Original Persian text \\
\hline 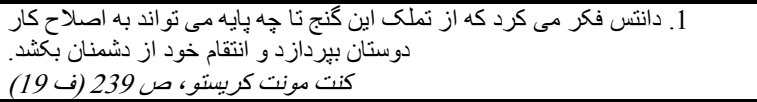 & \multirow{2}{*}{ 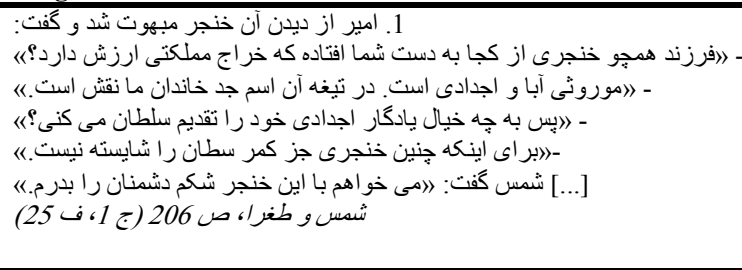 } \\
\hline 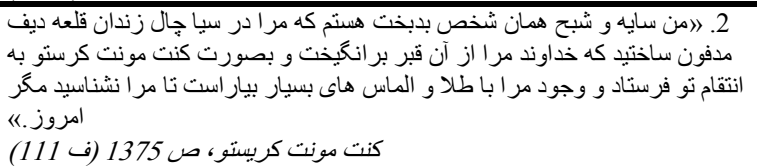 & \\
\hline
\end{tabular}

\section{Imitation of content 8}

The protagonists in both novels regard themselves as God's messenger.

\begin{tabular}{|c|c|}
\hline Translated text into Persian & Original Persian text \\
\hline 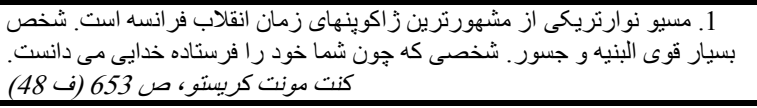 & \multirow{2}{*}{ 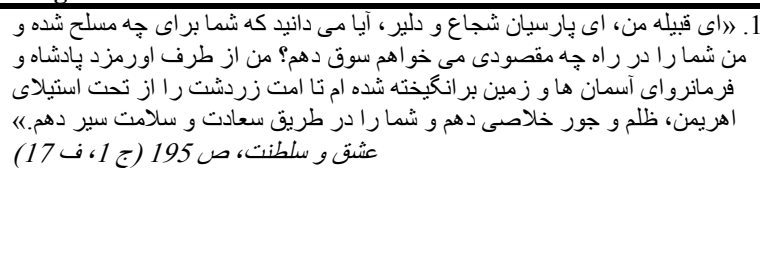 } \\
\hline 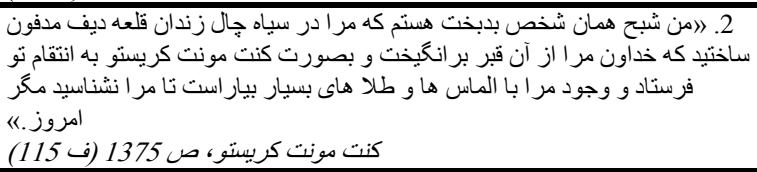 & \\
\hline
\end{tabular}




\section{Imitation in content 9}

In all three novels, the protagonists have been educated by a priest or a religious teacher.

\begin{tabular}{|c|c|}
\hline Translated text into Persian & Original Persian text \\
\hline Name of the educator: Abbé Faria & Name of the educator: Harbagess, Aži Dahāk 's minister \\
\hline \multirow[t]{3}{*}{ 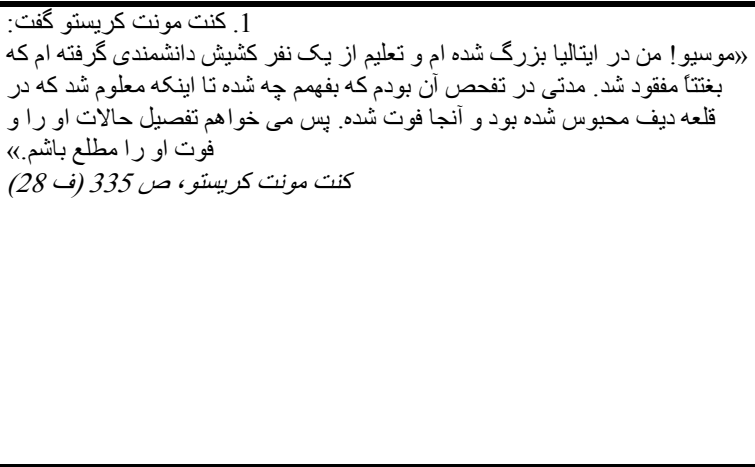 } & 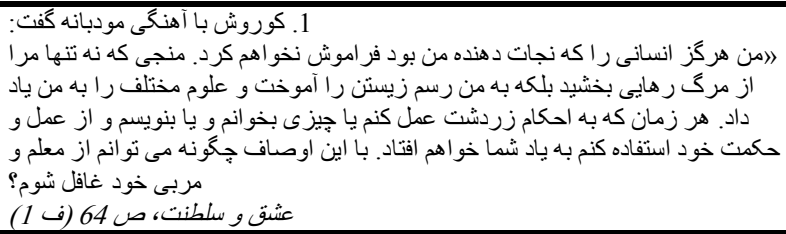 \\
\hline & Name of the educator: Baba Khorram \\
\hline & 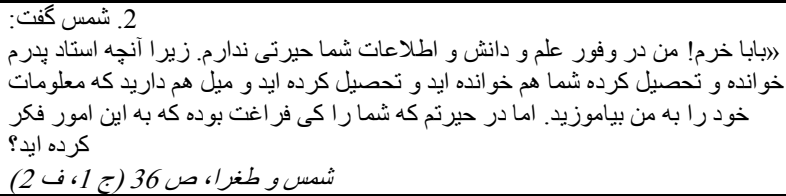 \\
\hline
\end{tabular}

\section{Imitation in content 10}

The protagonists in both novels served in the army; Shams served in the army of the Mongolians, but Morel served in the army of France. Ultimately, both of them left the army to render a service to their own families.

\begin{tabular}{|c|c|}
\hline Translated text into Persian & Original Persian text \\
\hline 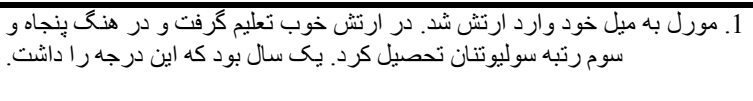 & \multirow{2}{*}{ 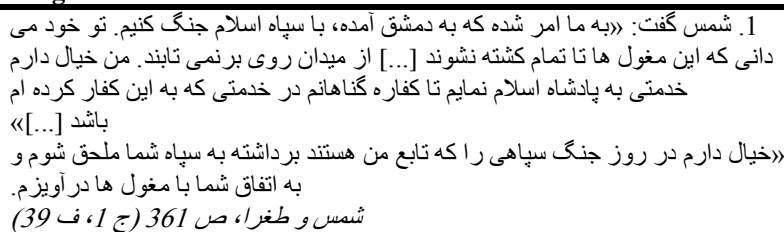 } \\
\hline 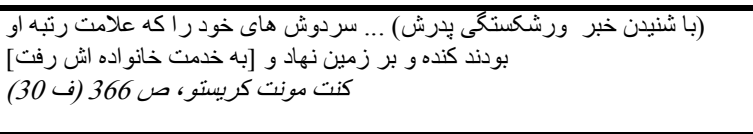 & \\
\hline
\end{tabular}

\section{Imitation of content 11}

In both novels, the tragedy for the princesses happens on the ship. In both the novels, the princesses are sold as slaves.

\begin{tabular}{|c|c|}
\hline Translated text into Persian & Pel \\
\hline 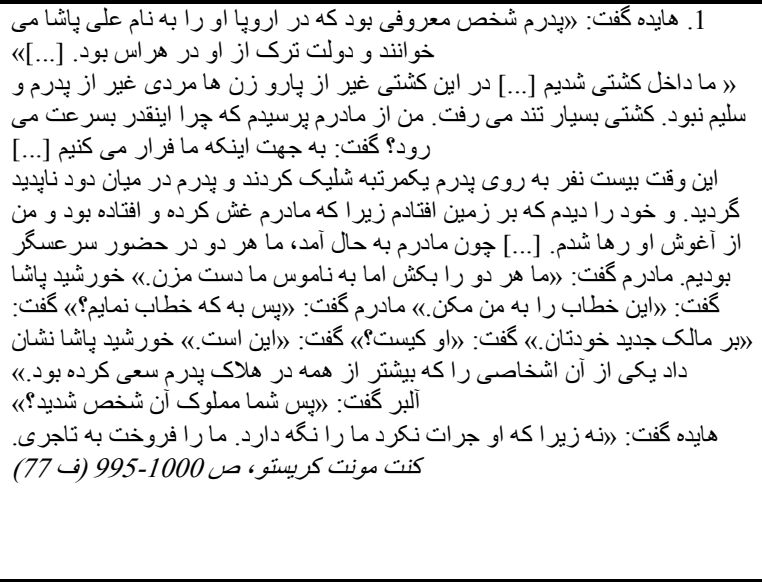 & 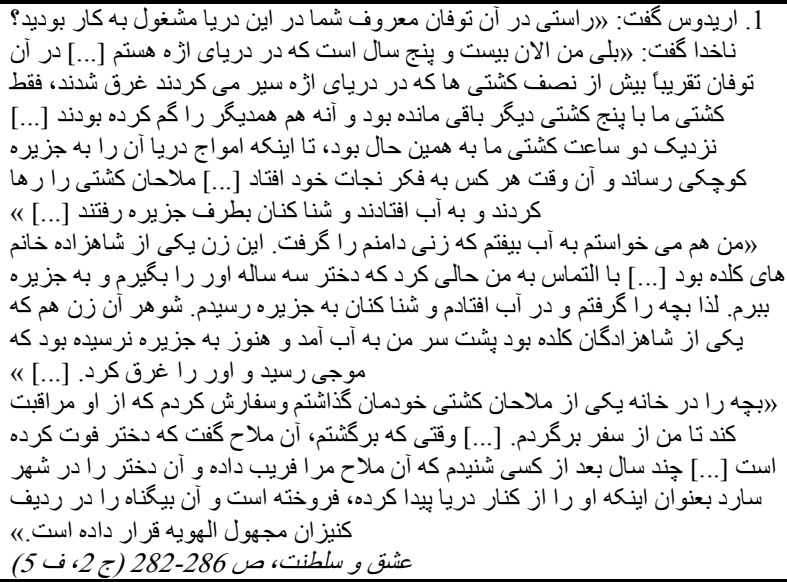 \\
\hline
\end{tabular}

\section{Imitation in content 12}

In both novels, the queens' love-affaire (queen of France and queen of Fars) have been depicted. 


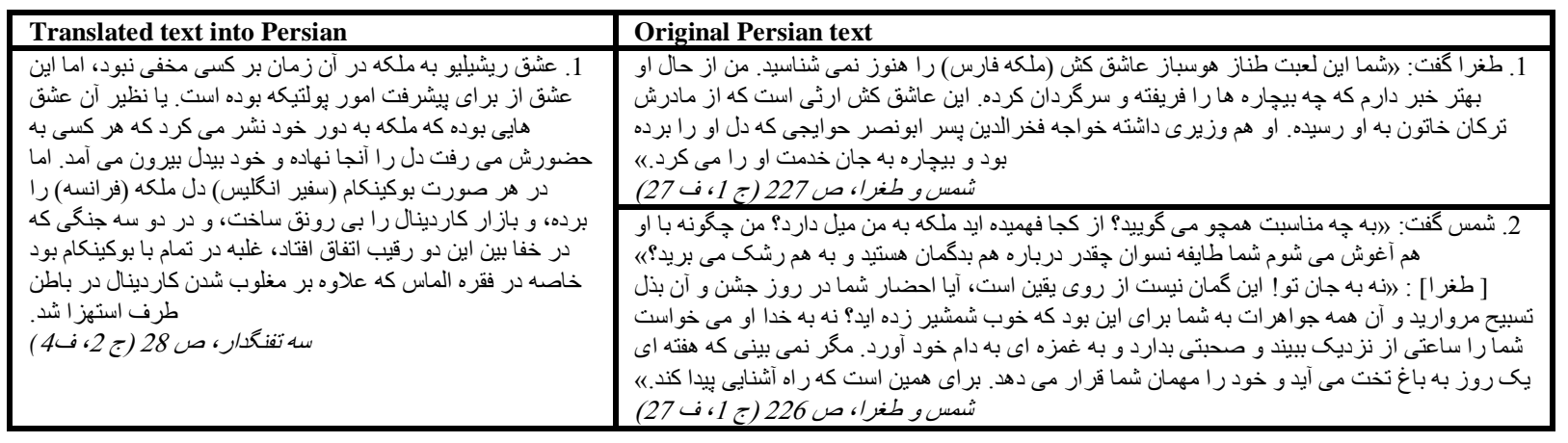

\section{CONCLUSION}

The rise of Persian novel was the focal point of the current research, which made the researchers carry out a corpusbased study. The two early novels produced in Iran (Shams-o-Toghra by Mohammad Bagher Khosravi and Eshgh-oSaltanat by Sheikh Mousa Naseri) were compared with translations of Alexandre Dumas' The Count of Monte Cristo and The Three Musketeers, aimed at proving the proposition that Dumas' novels have been imitated by the first Iranian novelists in both form and content in their novel production. The findings of this study confirm the proposition that French literary system had a profound impact on Persia Post-Constitutional Literary system. Since Shams-o Toghra and Eshgh-o Saltanat are the first experimentations of the the Iranian novelists, it is concluded that novel in Iran is the offspring of intersystemic interferences between Persian and French literary polysystems.

\section{REFERENCES}

[1] Balay C. (1998). The Origins of Persian Novel. Persian Trans. Gavimi M. and Khattat N. Tehran: Moin.

[2] Even-Zohar, I. (1990). Interference in dependent literary polysystems. Polysytem studies, 11(1), 79-83.

[3] Even-Zohar, I. (1990). Polysystem theory. Polysytem studies, 11(1), 9-26.

[4] Even-Zohar, I. (1990). System, dynamics, and interference in culture: A synoptic view. Polysytem studies, 11(1), 85-94.

[5] Even-Zohar, I. (1990). The literary system. Polysytem studies, 11(1), 27-44.

[6] Even-Zohar, I. (1990). The position of translated literature within the literary system. Polysystem studies, 11(1), 45-51.

[7] Even-Zohar, I. (1990). Translation and transfer. Polysystems studies, 11(1), 73-78.

[8] Mir Abedin H. (2007). A Hundred Years of Fiction Writing in Iran. Tehran: Nashr-e Cheshmeh.

[9] Munday, J. (2001).Introducing Translation Studies: Theories and Applications. London and New York: Rutledge.

[10] Sepanlou, M. (2002).The Pioneering Writers of Iran from the Constitutional Revolution to 1970: A Review on Novel, Short Story, Drama and Literary Criticism. Tehran: Negah.

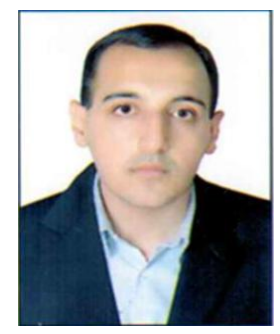

Abdollah Karimzadeh, born in Iran in 1985, holds an MA in translation studies (TS) from the Allameh Tabatabai University of Tehran. He is the author of many translations into Persian and into English including: Key Terms in Translation Studies by Giuseppe Palumbo, Theories for Classics by Louis Hitchcock, Novelist's Essential Guide to Crafting Scenes by Raymond Obstfeld, as well as numerous articles by scholars from Iran. $\mathrm{He}$ is also the author of many articles on comparative literature and translation studies. Mr. Karimzadeh is currently doing his $\mathrm{PhD}$ in comparative literature with "Interzones" Program in the Universities of Bergamo (Italy) and Eberhard Karls Universität Tübingen (Germany).

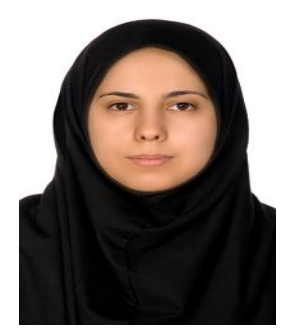

Elaheh Bayatzarand, born in Iran in 1983, holds an MA in Persian language and Literature from the Islamic Azad University Central Tehran Branch. As a researcher, she works on Immigration literature and comparative literature. 